\title{
A construção social da autoria de filmes publicitários
}

The social construction of authorship of advertising films

Tatiana Güenaga Aneas ${ }^{1}$

Resumo: Este artigo examina como se constrói o lugar da autoria no interior do campo do filme publicitário, considerando a atuação de instituições e profissionais envolvidos na criação destes produtos: agência publicitária, empresa anunciante e produtora audiovisual. A partir de uma perspectiva que tem como base a teoria dos campos de Bourdieu (1996), e em diálogo com autores que discutem autoria no campo da produção cultural, o trabalho busca discutir os lugares de autoria de filmes publicitários, com ênfase na relação entre instâncias criativa e produtora, e as vantagens de incorporar esta compreensão à análise desta espécie de obra audiovisual.

Palavras-chave: filme publicitário; campo publicitário; autoria.

Abstract: This article examines authorship within the field of advertising film, considering the operating of institutions and professionals involved in the creation of these products: advertising agency, advertiser and production company. From a perspective based on the field theory (Bourdieu, 1996), and in dialogue with authors who discuss authorship in the field of cultural production, the work aims to establish theoretical and methodological premises to understand the positions of authorship in advertising films, and the benefits of incorporating this understanding into the analysis of this kind of audiovisual work.

Keyworks: advertising film; advertising field; authorship.

1 Universidade Federal de Sergipe. Aracaju, SE, Brasil. E-mail: tatiana.aneas@gmail.com 


\section{Introdução}

Este artigo se debruça sobre a questão da autoria de filmes publicitários. Partindo de indagações sobre como se constrói e reproduz um possível lugar de autor(es) no interior do campo de produção publicitária, e sobre como compreender esta autoria nos auxilia a examinar estes filmes, na sua dimensão poética e estilística, propomos uma reflexão sobre este fenômeno, apoiada sobretudo em Bourdieu (1996) e nos seus estudos sobre Flaubert e o campo literário francês. Em diálogo com pesquisas que investigam autoria em campos outros da produção cultural, tais como o do cinema (JOST, 2009; RAMOS, 2004), da telenovela (SOUZA, 2004; SOUZA e WEBER, 2009), do videoclipe (BARRETO, 2009, 2014) e da própria publicidade (HANSEN, 2013), partimos da hipótese de que uma análise dos aspectos autorais de um filme publicitário deverá construir a história deste campo determinando a posição da agência, do anunciante e da produtora responsáveis pela criação dos filmes estudados, na relação com suas concorrentes, assim como as posições e disposições derivadas da trajetória social dos profissionais envolvidos na sua produção. Entender os filmes publicitários, temas, gêneros, estilos e instâncias autorais que os caracterizam, como a expressão de um ponto de vista, de uma tomada de posição das agências, anunciantes e produtoras, e dos criadores que atuam no interior destas empresas gera, assim, a necessidade de conhecer as posições de referência que teriam motivado que um filme apresentasse determinada constituição estilística, e não outra.

Assim, reconhecemos a necessidade de localizar tanto agência como anunciante e produtora no interior do que estamos aqui chamando de campo do filme publicitário porque supomos que, se é possível pensar em uma instância autoral no contexto da produção destes filmes, sua constituição atravessa a relação entre estas três instituições. Embora a concepção de um filme publicitário, sua ideia, seja de responsabilidade dos profissionais da criação publicitária, é cabível afirmar que uma parcela significativa do espaço de possibilidades de criação de uma agência, 
mesmo aquelas com alto grau de autonomia e reconhecido matiz autoral, é determinado pelo anunciante.

Por razões essencialmente pragmáticas, como o fato de que é o anunciante, cliente da agência, quem aprova a ideia, paga a produção e assina o filme. Mas também pelo fato de que essa empresa anunciante ocupa uma posição no seu próprio campo de origem, o que, por sua vez, irá determinar aquilo que é ou não possível a ela adotar enquanto discurso público através da publicidade, enquanto tomada de posição. Marcas, no contexto contemporâneo, possuem trajetória e personalidade, posicionam-se dentro de um mercado, no qual empresas anunciantes disputam espaço na forma de capital econômico, mas também simbólico. A posição que o anunciante ocupa neste espaço, é possível imaginar, está diretamente relacionada com a forma como ele se apresenta em suas campanhas e peças de comunicação, filmes entre elas. Neste trabalho, porém, o foco de análise recai preferencialmente sobre a instância de criação (agência publicitária) e suas relações com a instância anunciante (empresa) e a instância de produção (produtora audiovisual). O que não significa, sobremaneira, uma sugestão de que as instâncias anunciante ou produtora tenham menor importância na constituição deste lugar de autoria - até porque, como concluímos, localizar onde se encontra o maior grau de autonomia no interior de um processo criativo coletivo demanda a análise do caso específico.

\section{Origens e prolongamentos da noção de autoria}

Discussões sobre autoria são encontradas em abundância em praticamente todas as esferas da produção artística e cultural contemporâneas. Nos estudos literários, onde certamente esta preocupação tem sido vastamente debatida, a questão sobre quem produz um texto e quais as implicações sobre sua forma e conteúdo atravessa campos disciplinares de maneira a motivar a elaboração de modelos conceituais diversos, e cujo marco para as discussões contemporâneas se encontra no âmbito das críticas de Foucault, e na defesa de Barthes sobre a morte do autor. Guardados os distanciamentos entre as filiações teóricas dos dois 
autores, o que parece subjacente aos escritos tanto de um como de outro é uma certa inquietação com a vocação aplanadora e romântica que a noção de autor comumente, e praticada sobretudo pela crítica literária, teria sobre os textos. Sobre isso, o comentário de Barthes é claro ao afirmar que:

Dar um Autor a um texto é impor a esse texto um mecanismo de segurança, é dotá-lo de um significado último, é fechar a escrita. Esta concepção convém perfeitamente à critica, que pretende então atribuir-se a tarefa importante de descobrir o Autor (ou as suas hipóstases: a sociedade, a história, a psique, a liberdade) sob a obra: encontrado o Autor, o texto é "explicado", o crítico venceu [...] (BARTHES, 2004, p. 69).

Igualmente, em Foucault e sua noção de função-autor, é possível entrever um esforço, inclusive metodológico, de domar este constructo constituído historicamente com um estatuto quase sagrado e que esvazia os textos de autonomia, submetidos que seriam às intenções de seus autores.

O nome do autor não está localizado no estado civil dos homens, não está localizado na ficção da obra, mas na ruptura que instaura um certo grupo de discursos e seu modo singular de ser. Conseqüentemente, poder-se-ia dizer que há, em uma civilização como a nossa, um certo numero de discursos que são providos da função "autor", enquanto outros são dela desprovidos. Uma carta particular pode ter um signatário, ela não tem autor; um contrato pode ter um fiador, ele não tem autor. Um texto anônimo que se lê na rua em uma parede terá um redator, não terá um autor. A função-autor é, portanto, característica do modo de existência, de circulação e de funcionamento de certos discursos no interior de uma sociedade (FOUCAULT, 2001, p. 34).

Na crítica e na pesquisa acadêmica sobre cinema, o debate em torno da noção de autor se mantém desde a politique des auteurs, e se constitui como vasto campo de estudos, com prolongamentos que chegam ao campo da televisão e se ramificam para reflexões sobre autoria em 
produtos específicos como telenovelas, documentários e videoclipes2. Com abordagens que vão da análise textual ao culturalismo, o que emerge em comum no conjunto de estudos sobre autoria no audiovisual parece ser a concordância de que acepções apriorísticas sobre quem é o autor de um produto audiovisual pouco colaboram na compreensão da obra e do processo criativo que lhe dá origem. Para um analista cujas questões estejam centradas na obra em si, como era o caso de boa parte da semiologia dos anos sessenta, é perfeitamente possível deixar o autor “à porta das suas construções teóricas” (JOST, 2009, p. 11). Nesta pesquisa, porém, é colocado o desafio de enfrentar a questão da autoria e as formas como ela pode ser transposta para o exame de filmes publicitário.

Em verdade, importa aqui, mais do que atribuir uma autoria a um filme publicitário, procedimento estéril do ponto de vista da análise e dificilmente operacionalizável, entrever quais posições, dentre os vários agentes engajados no processo criativo, concentram os capitais necessários para tomar decisões, e em quais aspectos (temáticos, narrativos, estéticos, etc), sobre a composição do filme. Seguindo o percurso já trilhado por Souza (2004), Souza e Weber (2009), Ramos (2004), Nogueira (2002) e Barreto (2009, 2014), retornamos às premissas oferecidas pela teoria dos campos para refletir sobre o lugar do autor, o sentido social da autoria e as possíveis reverberações deste fenômeno na composição de filmes publicitários.

Assim, a hierarquia real dos fatores explicativos impõe inverter a progressão adotada ordinariamente pelos analistas: é preciso perguntar não como tal escritor chegou a ser o que foi - com o risco de cair na ilusão retrospectiva de uma coêrencia reconstruída - mas como, sendo dadas a sua origem social e as propriedades socialmente constituídas que ele lhe devia, pôde ocupar ou, em certos casos, produzir as posições já feitas ou por fazer oferecidas por um estado determinado do campo literário (etc.) e dar, assim, uma expressão mais ou menos completa e coerente das tomadas de posição que estavam inscritas em estado potencial nessas posições (por exemplo, no caso de Flaubert, as contradições inerentes à arte pela arte

2 Dentre os vários autores que se debruçam sobre o problema da autoria no audiovisual, podemos citar Bordwell (2003), Gerstner e Staiger (2003), Jean-Claude Bernardet (1994). 
e, de maneira mais geral, à condição de artista) (BOURDIEU, 1996, p. 244).

Em Meditações Pascalianas encontramos indicações semelhantes:

Porém, como distinguir tal leitura da projeção selvagem fundada em vagas analogias supostas, a que com frequência se entrega o lector (sobretudo quando pretende bancar o auctor, pensando e vivendo sua leitura como uma segunda "criação")? O esforço para se colocar no lugar do autor só se justifica quando se dispõe dos meios de construir esse lugar como tal, ou seja, uma posição, um ponto (princípio de um ponto de vista) num espaço social que não é senão o campo literário no interior do qual esse autor está situado (BOURDIEU, 2007, p. 106).

Retornamos aqui à ideia de que a posição social dos criadores envolvidos na produção dos filmes no interior do campo se define a partir dos capitais necessários para ocupá-la (em espécie e volume) e que tende a um determinado ponto de vista específico sobre o que é este campo. $\mathrm{O}$ autor individual ou coletivo, ou, como preferimos, instância autoral, é portanto um ponto neste espaço, e reconstruí-lo auxilia o analista a dar sentido às suas escolhas, presentes nos filmes na forma de estratégias compositivas, de mecanismos de produção de efeitos cognitivos, estéticos e afetivos. Sobre isso, Souza e Weber (2009), ao tratarem do papel do roteirista como autor de telenovelas, afirmam:

Interessa, sobremaneira, ampliar o conhecimento sobre as relações entre as condições sociais e históricas que propiciaram o reconhecimento dos roteiristas como autores de telenovelas no Brasil e os graus de poder de decisão que eles têm num sistema coletivo de criação audiovisual para escolherem e definirem as estratégias de composição dos programas de efeitos previstos nas histórias que criaram (SOUZA, 2009, p. 80).

Ressaltamos que, na esteira dos pesquisadores supracitados, partimos da premissa de que mesmo no contexto da produção audiovisual realizada no interior de grandes empresas e com forte caráter comercial, a condição autoral não necessariamente deriva de um controle absoluto sobre a obra por parte dos seus criadores. O que não impede, por 
outro lado, que os criadores tenham como critério de ação a busca por qualidade, buscando ajustar esta disposição às demandas mercadológicas - com maior ou menor afinco, a depender do seu próprio habitus, dos interesses que os movem e da posição que ocupam no campo. No caso do campo da produção audiovisual, cujas especificidades materiais demandam uma estrutura de equipamentos e uma diversidade de profissionais para sua realização, faz ainda menos sentido pensar em uma experiência de criação absolutamente dissociada de uma lógica industrial ou, minimamente, de divisão do trabalho. Sobre este ponto, Souza (2004), afirma:

O que estas reflexões reafirmam é a pertinência do foco de atenção das investigações sobre as relações entre as situações de trabalho dos realizadores e o processo de uma criação autoral, sobre as condições de um processo de trabalho que permita efetuar escolhas associadas a expressão de estilos e ao reconhecimento autoral. Considerações que apontam para a necessidade de ampliar o conhecimento sobre as condições do processo de criação e de reconhecimento da autoria na teledramaturgia. Conhecimento que ajude a compor categorias de análise mais precisas para enfrentar os limites interpretativos postos pelos estudos nesta área que insistem na antinomia inovação-repetição, desconsiderando as experiências autorais no âmbito da produção comercial massiva (SOUZA, 2004, p. 03).

O que Souza aponta é a necessidade de o analista conhecer o campo no qual estas instâncias autorais se inserem pois, apenas munido deste conhecimento, que permite alcançar o sentido da autoria no campo estudado, o analista tem condições de localizar mais precisamente as “experiências particulares de autoria" (2004, p. 04). Isso porque tais experiências são específicas de cada campo de produção, e dependem ainda do estado deste campo e do lugar em que se situa o agente ou grupo responsável pela obra. 


\section{Instâncias autorais no campo do filme publicitário}

No caso específico do campo da produção audiovisual publicitária, é possível delinear diferentes ocorrências de atribuição da autoria. Para o "grande público", ou melhor, para um público não especializado neste tipo de produto, na maioria dos casos, a instância autoral de um filme publicitário é a empresa anunciante. Como vai dizer Ramos (2004, p. 100), "a publicidade é um reino de anonimato para o público". Interessa notar com os termos "comercial" ou "vídeo publicitário" são mais comuns nesta esfera de recepção, uma vez que a palavra "filme", que remete ao universo mais "artístico" e valorizado do campo do cinema, é o que predomina nas esferas de recepção especializada, como é o caso das premiações e da crítica. Ao tratar, pelo viés da análise do discurso, sobre os tensionamentos presentes na autoria de campanhas publicitárias, Hansen (2013), conclui que:

[...] a voz que se sobressai do processo criativo do discurso publicitário, isto é, a voz que tem visibilidade no anúncio, é a do anunciante que assina a peça publicitária. Essa apreciação decorre de um fato analisado por nós anteriormente: o apagamento da distância entre o anunciante e o público-alvo, oportunizando a este último a ilusão de estar acessando diretamente o anunciante, sem a intermediação da agência de propaganda e seus profissionais. Previmos que essa voz se sobressai para o público-alvo (leitor real), geralmente leigo no assunto e consumidor em potencial da propaganda, no instante de contato com o anúncio final. Aos olhos desse leitor, o responsável pelo anúncio é o anunciante, que aparece ilusoriamente como autor (HANSEN, 2013, p. 149).

Como indica Hansen, o anunciante não apenas é um "autor ilusório" pelo fato de que são os profissionais da agência os responsáveis de fato pela concepção das peças publicitárias. Em muitos casos, a atuação do profissional que representa a empresa anunciante acontece muito mais no sentido de permitir ou vetar ideias, como uma espécie de gatekeeper. Quando a agência é detentora de um capital simbólico importante, porém, e é reconhecida pelo campo por sua habilidade criativa, há maior probabilidade de que o anunciante ceda às suas propostas, ainda que 
apresentem algum risco - situação condicionada à própria posição do anunciante, que influencia sua tendência ou não à inovação e ao risco associado. Barreto (2009) igualmente tensiona essa questão para tratar da autoria compartilhada entre instância performática (cantoras/es e bandas) e instância diretiva (diretores), típicas do campo de produção do videoclipe, trazendo à tona a ideia de que a autonomia para criar é derivada do capital simbólico acumulado, e que pode ser útil para pensar a autoria no campo do filme publicitário:

A consagração de um realizador dá-lhe mais relevância na defesa da especificidade e autonomia do contexto produtivo em que está inserido porque o imbui do poder de representante bem sucedido no processo concorrencial de seu próprio campo, estimulando seus propósitos de controlar a gestão artística de sua obra e reagir às pressões vindas de campos exógenos. No campo do videoclipe, diretores, cantores e bandas reconhecidos como autores podem, por exemplo, colocar-se contra a inclinação de gravadoras por fórmulas de sucesso, geralmente ligadas à cristalização de ideias pré-concebidas sobre como deve ser um clipe correspondente a certos gêneros musicais (BARRETO, 2014, p. 66).

De maneira homóloga, o campo do filme publicitário têm seus cânones e convenções. Os filmes de varejo são emblemáticos de posições a partir das quais criadores têm pouca autonomia para propor inovações. Estes cânones se organizam por formas discursivas conhecidas, como é o caso dos filmes baseados no testemunho de celebridades ou no apelo à autoridade (Vastergaard e Schroder, 1996, p. 97). A consagração, o reconhecimento, e o capital simbólico acumulado são em geral os indicadores de que uma agência ou criativo terão poder para propor e convencer o anunciante a apostar em ideias novas e a correr os riscos que a inovação acarreta.

Importa aqui chamar a atenção para outro aspecto da relação entre agência e anunciante: se, para o público em geral, agências e criativos eventualmente abrem mão de clamar para si a autoria dos filmes, o mesmo não se pode dizer do público especializado - ou seja, os próprios publicitários e profissionais da produção audiovisual publicitária, 
jornalistas e críticos especializados. Para estes, a autoria de um filme publicitário tende a ser da instância criativa, da agência (no plano institucional) e dos profissionais da sua equipe (no plano individual). Para constatar esta afirmação, basta consultar reportagens sobre filmes publicitários na imprensa especializada, que invariavelmente posicionam a agência na condição de instituição autora, adotando discursos como “AlmapBBDO assina novo filme da Volkswagen".

Da mesma forma, as premiações são em geral direcionadas para as agências, e são estas instituições que levam os troféus e angariam o maior quinhão de capital simbólico. Hansen (2013, p. 161) defende que, na dimensão do fazer efetivo, "a autoria é partilhada entre os profissionais da agência e o anunciante" e que "o processo criativo do discurso publicitário é uma manifestação coletiva por natureza”. Não discordamos de tal afirmação, mas acrescentamos que, a despeito de ser obra de criação coletiva nos termos descritos pelo autor (e na qual devemos inserir a produtora, no caso dos filmes), é para a agência e seus profissionais, da criação sobretudo, que esta autoria em geral tem maior valor e importância do ponto de vista de reconhecimento ${ }^{3}$.

Trata-se de uma noção de autoria não apenas subjacente às práticas da atividade publicitária e pressuposta por aqueles que participam deste campo, mas institucionalizada na forma de leis e regulamentos. $\mathrm{O}$ texto do decreto 57.690 de lo de fevereiro de 1966, que regulamenta lei no 4.680 de 18 de junho de 1965, dispondo sobre a profissão de publicitário, é claro no que diz respeito a quem é o proprietário das ideias presentes em filmes e campanhas:

A idéia utilizada na propaganda é, presumidamente, da Agência, não podendo ser explorada por outrem, sem que aquela, pela exploração, receba a remuneração justa, ressalvado o disposto no art. 454, da Consolidação das Leis do Trabalho. (inciso VIII, artigo 9o, seção la)

3 Tanto é que são as agências que pagam pelas inscrições nos prêmios. Na edição de 2014 do evento, a AlmapBBDO investiu cerca de 120 mil euros em inscrições de peças. Fonte: (RECLAME, 12 ago. 2014) 
As Normas-Padrão da Atividade Publicitária, publicadas pelo CENP (Conselho Executivo de Normas-Padrão), também traz indicações de que, neste campo, é sobre a agência (e seus profissionais) que deve recair o reconhecimento de autoria das peças publicitárias:

Como estímulo e incentivo à criatividade, presume-se que as idéias, peças, planos e campanhas de publicidade desenvolvidos pertençam à Agência que os criou, observada a legislação sobre o direito autoral (CENP, 1998, p. 09).

\section{Autoria como resultado de disputas por capital simbólico}

Convém nos determos brevemente sobre como se estabelecem as relações de poder e divisão do trabalho no interior das agências no processo de criação de um filme. Isso porque, mesmo no interior da agência, o reconhecimento da autoria de um filme não é necessariamente um processo simples e pacífico. As fichas técnicas dos filmes parecem ser um indicador interessante desta disputa e das posições dominantes no seu interior. Nos créditos, que circulam através da imprensa especializada por divulgação das próprias agências, a ordem de apresentação das informações diz muito da importância atribuída aos profissionais no processo de criação e produção do filme. Geralmente, após o título do filme, anunciante e produto, a primeira função elencada é a do diretor de criação, seguida da dupla de criação (redator e diretor de arte), produtora e diretor de cena. As funções técnicas, em geral de profissionais da produtora, vêm em seguida. Sobre como as fichas técnicas são importante instrumento de reconhecimento de autoria individual, o publicitário Marcello Serpa diz, em entrevista ao Meio \& Mensagem:

E, no mercado de criação, é fundamental que se tenha um respeito profundo sobre duas coisas. A primeira é bem de publicitário, de criativo, que é o respeito pela ficha técnica, que significa respeitar a autoria e jamais colocar seu nome à frente do trabalho dos outros. O diretor de criação que coloca o nome dele à frente de todo e qualquer trabalho que aparece na 
agência está achatando os talentos que atuam com ele. Essa é uma prática comum no mundo todo (SERPA, 2015).

Por uma questão hierárquica, o diretor de criação é apontado, nas fichas técnicas, como principal responsável pelo filme - muito embora a ideia propriamente não seja geralmente dele, e sim da dupla de criação que lhe é subordinada. Deste profissional, espera-se que seja capaz de reconhecer, nas propostas apresentadas pelas duplas, aquela que tem potencial para se tornar um filme que irá atender às demandas do anunciante e garantir reconhecimento para si, sua equipe e sua agência.

Possivelmente pela importância do roteiro como instrumento primeiro de materialização da ideia de um filme, alguns pesquisadores atribuem uma autoria suposta ao redator, responsável por sua escrita. Ramos (2004, p. 98), questiona "quem é o criador da "obra" de 30 segundos, o redator ou o diretor?", transpondo para a publicidade uma tensão entre roteirista e diretor típica do campo do cinema. Baggio (2009, p. 154) segue a mesma trilha, ao evocar "a morte do autor/redator publicitário". O processo de concepção da ideia do filme, porém, nas práticas atuais das agências, cabe à dupla de criação, sendo indistinguível a origem precisa da ideia do ponto de vista do indivíduo, salvo raros casos em que é expressa. Em um dos poucos manuais de roteiro para filmes publicitários disponíveis no Brasil, Barreto (2004), resume bem como esse processo acontece:

Atualmente, existe nas agências de publicidade, a ideia de que escrever roteiro é tarefa do redator. [...] Escrever o roteiro, porém, é apenas a última fase de sua elaboração. É a fase técnica. Há alguma coisa que vem antes do conhecimento sobre como se constroem diálogos eficientes e como se separam cenas. Essa "coisa" é o elemento básico do roteiro, é do que depende a elaboração de sua estrutura. A coisa é a ideia. E com a ideia não há discussão: em uma campanha, ela é responsabilidade tanto do redator como do diretor de arte (BARRETO, 2004, p. 25).

O já citado Marcello Serpa, originalmente diretor de arte, teve autoria atribuída a muitos filmes ao longo de sua carreira, por exemplo. 
Algumas agências adotam hoje um esquema de trabalho em que equipes multidisciplinares se dedicam a um ou alguns clientes, fazendo com que esta autoria pressuposta do redator caia por terra. Do ponto de vista do reconhecimento social, a autoria de um filme publicitário, no interior da agência, é atribuída à dupla que assina a criação e seu diretor ou superior hierárquico. Do ponto de vista de premissas analíticas, esta constatação nos conduz à análise da trajetória destes agentes, e sobretudo da posição que ocupam no momento da emergência do filme estudado.

\section{Agência e produtora: entre o conflito e a parceria}

Por fim, é necessário nos determos sobre as relações que se estabelecem entre agência e produtora audiovisual. Esta relação, muito bem descrita por Ramos (2004), tende a deslizar entre a parceria e o conflito. Isso decorre, sobretudo, do fato de que os agentes do campo do audiovisual (pensando no diretor, principalmente) têm aspirações artísticas talvez ainda mais acentuadas do que os criativos das agências. Em geral, por circularem em campos vizinhos como o do cinema, onde a autoria do diretor é suposta, para atuar no campo do filme publicitário este profissional tem de estar disposto a, ao menos, compartilhar este lugar.

Por outro lado, o campo do filme publicitário é o lugar em que profissionais do audiovisual podem encontrar recursos muitas vezes raros em outros espaços - comparando com as possibilidade de atuação no cinema brasileiro, sobretudo até os anos noventa, esta diferença é ainda mais relevante. Ramos contrapõe estes dois cenários que se colocam para os profissionais do audiovisual no Brasil: de um lado, um fazer cinematográfico mais autônomo em termos de concepção, mas limitado pelas dificuldades de recursos técnicos, e pelo baixo retorno econômico; de outro, a subordinação inerente à tarefa de filmar a ideia de outrem, porém com a possibilidade de ter acesso a uma estrutura superior de produção, em um campo que preza pelo cuidado estético das suas obras. 
Mas, compensando esse lado negativo, a atividade tem uma face que é atrativa: a busca do domínio do fazer cinematográfico, do apuro técnico, são positividades em relação à publicidade para se manter uma constante atualização audiovisual (RAMOS, 2004, p. 94).

Com frequência, a produção de filmes publicitários é relatada como um espaço de aprendizagem e renovação, por parte dos profissionais da área. Um diretor poderá ter neste espaço um lugar de experimentação estética que o cinema ou a televisão proporcionarão com menor frequência. Ridley Scott, um reconhecido diretor de longa-metragens, começou sua carreira na publicidade e, ainda hoje, mantém um volume significativo de produções nesta área, em paralelo à atuação no cinema.

I loved doing commercials. I loved turning footage, and loved the fact that commercials were on film. I loved how they were all visual. To me, advertising films were little capsules of perfection. You also got an opportunity to craft a 30-second commercial much more often than you did a 60-minute television film4 (SAMMON, 1999, p. 29).

Muito embora exista de fato uma disputa pelo controle sobre o resultado da obra, sobretudo entre criativos e diretores, é igualmente verdade que alguns aspectos da maneira como o processo produtivo de filmes publicitários se cristalizou no Brasil acaba favorecendo a instância realizadora, em termos de liberdade e autonomia relativas. Nos mercados americano e inglês, a concorrência e o nível de especialização exigido acaba classificando os diretores por segmentos, engessando sua atuação (BERTOMEU, 2011, p. 127). Além disso, nestes países, é muito mais comum o acompanhamento da equipe de criação no set, o que no Brasil acontece mais raramente, até por conta do volume de trabalho que muitas vezes impede criativos de deixar a agência.

$\mathrm{Na}$ interpretação do roteiro para a construção do audiovisual da peça, existe pouca clareza nos comandos e nas decisões. O domínio da técnica

4 "Eu amava fazer comerciais. amava alternar os formatos e amava o fato de que comerciais eram em película. Eu amava como eles eram puramente visuais. Para mim, filmes publicitários são pequenas cápsulas de perfeição. Sem contar que você tem oportunidade de filmar comerciais de 30 segundos com muito mais frequência do que filmes de 60 minutos para televisão" (tradução nossa). 
permite que os diretores façam contribuições consistentes e decidam sobre muitos aspectos de pouco domínio do publicitário (BERTOMEU, 2011, p. 138).

Isso porque, embora animatics e/ou storyboards prevejam de maneira geral as cenas e sequências do filme, são pouco específicos em termos de cor, textura e iluminação, movimentos de câmera, ritmo de edição. Mesmo parâmetros plásticos como escala de planos e enquadramentos, em tese previstos nos documentos fornecidos pela agência, são passíveis de mudanças. O depoimento de Washington Olivetto reforça esta ideia:

Costumo, desde o início da minha vida na publicidade, depositar total confiança nos profissionais que escolho para trabalhar comigo e dar total liberdade a eles, fato que talvez explique a maior parte dos meus acertos. No caso da produção de comerciais, digo ao diretor o que quero do filme, mas deixo que ele escolha a equipe, faça o casting, a luz, as locações, os cenários, as angulações, os critérios de edição, a trilha, os ruídos incidentais, tudo (OLIVETTO, 2008, p. 45).

Em verdade, é esta a contribuição que se espera de um diretor de filmes publicitários, que, captadas as linhas gerais da criação, ele controle e tome as decisões relativas sobretudo à dimensão estética do filme. É nesta dimensão, portanto, que o analista que examina um filme pode em geral verificar a presença da instância realizadora, na forma de escolhas que se traduzem em estratégias de efeitos de ordem sobretudo estética. Evidente que esta reflexão não se aplica a todos os casos mas, antes, aponta uma tendência de funcionamento das relações entre agência, anunciante e produtora. Isso porque é também verdade que, para ter a possibilidade de trabalhar com determinados realizadores, eventualmente a agência e os criativos terão de abrir mão da sua própria autonomia e delegar a etapa de concepção também à instância produtora. Dentre outros, é possível pensar na série de curtas-metragens "The Hire" (Fallow/BMW/BMW Films, Anonymous Content, Zeta Films, RSA Films, 2001, EUA), cujos episódios (divididos em duas temporadas) 
foram escritos e dirigidos por cineastas reconhecidos e em cuja produção a ingerência da agência foi mínima, por exigência dos diretores.

\section{Conclusões}

A título de síntese, este artigo se ocupou de discutir o lugar das instâncias envolvidas no processo de criação, aprovação e produção de filmes publicitários, apostando que este conhecimento amplia as possibilidade de o analista desta espécie de produto localizar escolhas poéticas, estéticas, narrativas e temáticas presentes nestes filmes e que possam ser relacionadas às posições destas instituições e profissionais no campo da produção de filmes publicitários.

Ao lidar com um filme particular, a compreensão do lugar do anunciante no seu campo enriquece a análise não apenas no sentido de entender como sua emergência foi possível, mas também no que diz respeito às formas como o discurso sobre a marca se insere na narrativa. A instância criativa, por sua vez, tende a ser o lugar das escolhas temáticas e narrativas sobre o filme, uma vez que cabe à agência publicitária e à equipe de criação a concepção da obra, sua ideia geral, seu roteiro e indicações primeiras de estilo visual. Por fim, problematizar a autoria de um filme publicitário imprescinde de compreender o lugar da produtora audiovisual. Embora trate-se de uma instância que supostamente teria menor autonomia criativa, uma vez que sua função seria executar a ideia criada por outros, a análise da posição e trajetória dos profissionais ligados à produtora mostra-se um procedimento fundamental para entender muitos aspectos do estilo, sobretudo estético, destes filmes.

Em suma, defende-se aqui uma postura analítica que contemple aspectos textuais e contextuais de filmes publicitários como estratégia para melhor compreender como as escolhas criativas de agentes concretos reverbera na composição destes materiais. E que, igualmente, as instâncias anunciante, criativa e produtora fazem necessariamente parte deste processo, sendo a autoria atribuído de um filme publicitário uma construção social derivada das relações de poder entre estas instituições e agentes que nelas atuam. Por fim, ressaltamos que esta reflexão propõe 
tendências e premissas gerais para uma análise de tal natureza, que deve ser empreendida na lida empírica com casos particulares de produções audiovisuais concretas.

\section{Referências}

BARRETO, R. R. Parceiros no clipe: a atuação e os estilos autorais de diretores e artistas musicais no campo do videoclipe a partir das colaborações Mondino/Madonna e Gondry/Björk. 2009. 230 f. Tese (Doutorado) - Programa de Pós-graduação em Comunicação e Cultura Contemporâneas, Universidade Federal da Bahia, Salvador, 2009.

BARRETO, R. R. A construção social da autoria nos videoclipes. In: BARRETO, R. R.; SOUZA, M. C. J. (Orgs.). Bourdieu e os estudos de mídia: campo, trajetória e autoria. Salvador: Edufba, 2014. p. 41-80.

BARRETO, T. Vende-se em 30 segundos: manual do roteiro para filme publicitário. São Paulo: Editora Senac São Paulo, 2004.

BARTHES, R. O rumor da língua. São Paulo: Martins Fontes, 2004.

BRASIL. Lei n 4.680, de 18 de junho de 1965. Dispõe sôbre o exercício da profissão de Publicitário e de Agenciador de Propaganda e dá outras providências. Disponível em: <http://www.planalto.gov.br/ccivil_03/LEIS/L4680.htm>. Acesso em: 5 jan. 2016.

BRASIL. Decreto ${ }^{\circ} 57.690$, de lo de fevereiro 1966. Aprova o Regulamento para a execução da Lei n ${ }^{\circ}$ 4.680, de 18 de junho de 1965. Disponível em: <http://www.planalto. gov.br/ccivil_03/decreto/D57690.htm>. Acesso em: 5 jan. 2016

BERNARDET, J. C. O autor no cinema. São Paulo: Editora da USP, 1994.

BERTOMEU, J. V. C. Criação em filmes publicitários. São Paulo: Cengage Learning, 2010.

BORDWELL, D. Authorship and narration in art cinema. Rutgers: Rutgers University Press, 2003.

BOURDIEU, P. As regras da arte: gênese e estrutura do campo literário. São Paulo: Companhia das Letras, 1996.

Meditações pascalianas. Rio de Janeiro: Bertrand Brasil, 2007.

CONSELHO EXECUTIVO DAS NORMAS-PADRÃO. Normas Padrão da Atividade Publicitária. 1998. Disponível em: <http://www.cenp.com.br/PDF/NomasPadrao/Normas_Padrao_Portugues.pdf $>$. Acesso em: 5 jan. 2016.

FOUCAULT, M. O que é um autor? In: MOTTA, M. B. (Org.). Ditos e escritos. Estética: literatura e pintura, música e cinema. Rio de Janeiro: Forense Universitária, 2001. p. 144-162.

GERSTNER, D.; STAIGER, J. Authorship and film. New York: Routiedge, 2003. 
HANSEN, F. (In)verdades sobre os profissionais de criação: poder, desejo, imaginação e autoria. Porto Alegre: Entremeios, 2013.

JOST, F. O autor nas suas obras. In: SERAFIM, J. F. (Org.). Autor e autoria no cinema e na televisão. Salvador: EDUFBA, 2009. p. 11-32.

NOGUEIRA, L. O autor na televisão. Goiânia: Editora da UFG; São Paulo: Edusp, 2002.

RAMOS, J. M. O. Cinema, televisão, publicidade: cultura popular de massa no Brasil nos anos 1970-1980. São Paulo: Annablume, 2004.

SAMMON, M. P. Ridley Scott close up: the making of his movies. Nova Iorque: Thunder's Mouth Press, 1999.

SERPA responde a 20 personalidade. Meio \& Mensagem. 27 ago. 2015. Disponível em: $<$ http://www.meioemensagem.com.br/mob/comunicacao/interna.html?path=/home/ comunicacao/noticias/2015/08/27/Serpa-responde-a-20-personalidades $>$. Acesso em: 5 fev. 2016.

SOUZA, M. C. J. Analisando a autoria das telenovelas. In: SOUZA, M. C. (Org.). Analisando Telenovelas. Rio de Janeiro: E-papers, 2004, p. 11-52.

SOUZA, M. C. J.; WEBER, M. H. Autoria no campo das telenovelas brasileiras: a política em "Duas caras" e em "A favorita”. In: SERAFIM, J. F. (Org). Autor e autoria no cinema e na televisão. Salvador: EDUFBA, 2009. p. 79-120

VESTERGAARD, T.; SCHRODER, K. A linguagem da propaganda. São Paulo: Martins Fontes, 1996.

\section{Sobre a autora}

Professora efetiva do Departamento de Comunicação Social da Universidade Federal de Sergipe. Colaboradora do Programa de Pós-graduação em Comunicação da UFS. Doutora em Comunicação e Cultura Contemporâneas pelo Póscom/Universidade Federal da Bahia (2016). Mestre em Comunicação e Cultura Contemporâneas pela mesma instituição (2011). Especialista em Design de Comunicação Social pela Universidade Salvador (2009). Graduada em Comunicação Social com habilitação em Jornalismo pela Universidade Federal da Bahia (2007).

Data de submissão : 15/01/2017

Data de aceite : 02/02/2018 